\title{
Effect of Long-Term Whole Body Vibration Training on Visceral Adipose Tissue: A Preliminary Report
}

\author{
Dirk Vissers ${ }^{a, b . c}$ \\ Steven Truijen ${ }^{\mathrm{a}}$ Luc Van Gaal ${ }^{\mathrm{b}, \mathrm{c}}$ \\ ${ }^{a}$ Department of Health Sciences - Physiotherapy, University College of Antwerp, \\ ${ }^{b}$ Faculty of Medicine, University of Antwerp, \\ ${ }^{c}$ Department of Endocrinology, Diabetology and Metabolism, Antwerp University Hospital, Antwerp, Belgium
}

\section{Key Words}

Exercise therapy - Metabolic syndrome X . Overweight . Vibration - Visceral adipose tissue

\section{Summary}

Aim: To determine the effect of whole body vibration (WBV), combined with caloric restriction, on weight, body composition and metabolic risk factors in overweight and obese adults. Methods: A randomized, controlled study with a 6-month intervention period and a 6-month 'no intervention' follow-up. 61 of the 79 participants completed the study. Data were collected at baseline and at 3, 6 and 12 months in the control group (CONTROL), the diet only group (DIET), the diet plus fitness group (FITNESS) and the diet plus WBV group (VIBRATION). Results: Weight decreased significantly in all three intervention groups. Only FITNESS and VIBRATION managed to maintain a weight loss of $5 \%$ or more in the long term. Visceral adipose tissue (VAT) changed most in VIBRATION: $-47.8 \pm 41.2$ and $-47.7 \pm 45.7 \mathrm{~cm}^{2}$ after 6 and 12 months respectively compared to CONTROL $\left(-3.6 \pm 20.5\right.$ or $\left.+26.3 \pm 30.6 \mathrm{~cm}^{2}\right)$, DIET $(-24.3 \pm 29.8$ or $\left.-7.5 \pm 28.3 \mathrm{~cm}^{2}\right)$ and FITNESS $(-17.6 \pm 36.6$ or $-1.6 \pm$ $33.3 \mathrm{~cm}^{2}$ ) ( $\left.<0.001\right)$. Conclusions: Combining aerobic exercise or WBV training with caloric restriction can help to achieve a sustained long-term weight loss of 5-10\%. These preliminary data show that WBV training may have the potential to reduce VAT more than aerobic exercise in obese adults, possibly making it a meaningful addition to future weight loss programs.

\section{Introduction}

In the past 10 years the prevalence of obesity has increased by $10-40 \%$ in the majority of European countries, resulting in more than $50 \%$ of the people being overweight or obese [1]. In the USA the prevalence of obesity has increased by more than $75 \%$ since 1980 [2]. Obesity, abdominal obesity in particular, plays a central role in the metabolic syndrome which is known as a cluster of risk factors associated with adverse cardiovascular outcomes [3-5.] The Adult Treatment Panel III (ATP III) defines adult metabolic syndrome as 3 or more of the following abnormalities: hypertriglyceridemia, low highdensity lipoprotein cholesterol (HDL-C), impaired fasting glucose, excessive waist circumference and hypertension [6]. International guidelines state that a weight loss of $5-15 \%$ over a period of 6 months is realistic and of proven health benefit [7]. It has been previously described that even moderate weight loss has a beneficial effect on cardiovascular risk factors in overweight people when combined with exercise and is associated with improvement of all aspects of metabolic syndrome $[8,9]$. Several studies suggest that exercise alone is a rather inefficient means of weight loss [10-12]. However, exercise seems to play a more crucial part in the maintenance of weight loss [12-14]. Aerobic exercise has been described to have a potential in providing a modest weight loss, as where resistance training can provide some conservation of fat free mass during weight loss by dieting [15]. It is also reported that high levels of cardiorespiratory fitness are associated with lower risk of metabolic syndrome [16]. Also muscular strength has been reported to be inversely associated with metabolic syndrome incidence [17]. However, it is less clear to what extent the addition of different, less conventional forms of aerobic exercise or resistance training to a diet can improve the

\begin{tabular}{ll}
\hline KARGER & $\oplus$ c 2010 S. Karger GmbH, Freiburg \\
Fax +497614520714 & Accessible online at: \\
Information@Karger.de & www.karger.com/ofa \\
www.karger.com &
\end{tabular}


Table 1. Characteristics of the 4 groups at baseline

\begin{tabular}{lccccc}
\hline & $\begin{array}{l}\text { Control } \\
(\mathrm{n}=21)\end{array}$ & $\begin{array}{l}\text { Diet } \\
(\mathrm{n}=20)\end{array}$ & $\begin{array}{l}\text { Fitness } \\
(\mathrm{n}=20)\end{array}$ & $\begin{array}{l}\text { Vibration } \\
(\mathrm{n}=18)\end{array}$ & $\mathrm{P}$ \\
\hline Age, years & $44.8 \pm 11.4$ & $45.5 \pm 13.1$ & $44.7 \pm 13.0$ & $43.3 \pm 9.6$ & 0.951 \\
Weight, $\mathrm{kg}$ & $88.6 \pm 15.9$ & $92.1 \pm 11.1$ & $94.5 \pm 11.7$ & $95.2 \pm 17.8$ & 0.480 \\
$\mathrm{BMI}, \mathrm{kg} / \mathrm{m}^{2}$ & $30.8 \pm 3.4$ & $32.9 \pm 3.1$ & $33.1 \pm 3.4$ & $31.9 \pm 4.7$ & 0.209 \\
VAT, $\mathrm{cm}^{2}$ & $125.7 \pm 62.5$ & $124.5 \pm 50.9$ & $113.2 \pm 45.3$ & $150.4 \pm 78.7$ & 0.294 \\
WC, $\mathrm{cm}$ & $99.7 \pm 11.1$ & $102.3 \pm 7.9$ & $103.5 \pm 9.4$ & $100.0 \pm 13.5$ & 0.653 \\
WHR & $0.91 \pm 0.11$ & $0.90 \pm 0.07$ & $0.90 \pm 0.09$ & $0.88 \pm 0.11$ & 0.760 \\
$\mathrm{VO}_{2} \mathrm{max}, \mathrm{ml} / \mathrm{kg} / \mathrm{min}$ & $\mathrm{N} / \mathrm{A}$ & $22.0 \pm 2.6$ & $24.2 \pm 2.5$ & $27.9 \pm 7.1$ & 0.008 \\
\hline
\end{tabular}

$\mathrm{VAT}=$ Visceral adipose tissue $\mathrm{WC}=$ waist circumference; $\mathrm{WHR}=$ waist-to-hip ratio,

$\mathrm{VO}_{2} \max =$ maximal aerobic capacity. different components of the metabolic syndrome. The increasing interest in whole body vibration (WBV) of commercial fitness clubs has evolved into a move toward the use of WBV exercise as an alternative way of resistance training. WBV is implemented through the use of a vibrating platform on which exercises can be performed. The vibrations generated by the engines underneath the platform are transmitted to the person standing, sitting or lying on the machine. The amplitude and frequency of these vibrations can be set on the device. Reviewing the literature, Rehn et al. [18] stated strong to moderate evidence for the effects of long-term WBV exercise on the leg muscular performance among untrained people and elderly women with no clear evidence for effects on muscular performance after short-term vibration stimuli. It has been suggested that WBV is an effective training method in order to improve maximal strength [19]. Evidence of effect of WBV on visceral adipose tissue (VAT) in animals has generated the question concerning a possible clinical use of WBV in the treatment of obesity [20]. To the best of our knowledge, there are no published studies that evaluate the long-term effect of WBV on weight, body composition or metabolic factors in overweight and obese adults.

Our objective was to study if adding either fitness or WBV training to diet counseling during 6 months could decrease body weight and improve body composition and metabolic risk factors.

\section{Material and Methods}

\section{Subject Characteristics}

A total of 79 subjects with overweight or obesity were recruited, and 61 of them completed the study. 58 overweight and obese adults, recruited in a outpatient clinic and through media advertising, were randomized into 3 intervention groups that were matched for BMI category and gender: a diet only group (DIET), a diet + fitness training group (FITNESS) and a diet + WBV group (VIBRATION). A control group (CONTROL) of 21 overweight and obese adults was also recruited through media advertising. Exclusion criteria included: diabetes, pregnancy, treatment with tricyclic antidepressants, joint replacement orthopedic surgery, use of weight loss drugs, endocrine conditions causing weight change, BMI $>40 \mathrm{~kg} / \mathrm{m}^{2}$, weight loss $>5 \%$ of body weight within 6 weeks prior to start of the study.
Subjects were also excluded if they were unable or unwilling to perform physical exercise for any reason or if the resting electrocardiogram (ECG) was abnormal.

Subject characteristics are shown in table 1. All patients were clinically examined by a physician and shown to be generally in good health. The study was approved by the ethical committee of the Antwerp University Hospital, and all patients gave their informed consent.

\section{Anthropometric Measurements}

All measurements were performed in the morning, with patients in fasting conditions and undressed. Height was measured to the nearest $0.5 \mathrm{~cm}$, and body weight was measured with a digital scale to the nearest $0.1 \mathrm{~kg}$. BMI was calculated as weight in $\mathrm{kg}$ over height in $\mathrm{m}^{2}$. Waist circumference was measured at the mid-level between the lower rib margin and the iliac crest. Hip circumference was measured at the level of the trochanter major and the waist-to-hip ratio (WHR) was calculated. Body composition was determined by bioimpedance analysis as described by Lukaski et al. [21], and fat mass percentage was calculated using the formula of Deurenberg et al. [22]. This technique measures the total fat percentage of the body without making a distinction between peripheral subcutaneous, abdominal subcutaneous, or deep abdominal fat. Because the amount of VAT has been suggested to be associated with an increased cardiovascular risk, we estimated the amounts of total abdominal adipose tissue and visceral abdominal adipose tissue separately by a CT scan at the L4 through L5 level according to previously described methods [23]. Systolic and diastolic blood pressures were determined on the right arm of the patient, after at least 5 min resting, using a mercury sphygmomanometer. The full assessment, including CT scan, was repeated at 3, 6, and 12 months.

\section{Laboratory Analyses}

A fasting blood sample was taken from an antecubital vein between 8:00 and 10:00 AM after starting interventions to determine fasting levels of lipids (triglycerides and HDL-C) and glucose. A minimal oral glucose tolerance test was performed with $75 \mathrm{~g}$ of glucose, with blood samples taken to determine glucose and insulin in the fasted state and $2 \mathrm{~h}$ after the glucose load. Plasma glucose and triglycerides were measured on Vitros 750 XRC (Ortho Clinical Diagnostics, Johnson and Johnson, Buckinghamshire, UK). HDL-C was measured on Roche/Hitachi 912 (Roche Diagnostics, Mannheim, Germany). Insulin levels were measured with the Medgenix two-site IRMA assay (BioSource, Nivelles, Belgium).

Exercise Test

Lung function was assessed by spirometry, and each subject had a resting ECG. Each subject performed an incremental exercise test on an elec- 
tronically braked bicycle ergometer (Schiller, Baar, Switzerland) that was factory calibrated. Resting measurements were taken with the subject seated on the ergometer. The first power output was $30 \mathrm{~W}$, and the power was increased by $15 \mathrm{~W}$ each minute until the subject reached a symptomlimited maximal power output. Exhaled air was analyzed to determine metabolic gas exchange with a respiratory mass spectrometer (type EOS Sprint; Erich Jaeger, Friedberg, Germany). Ventilation (VE), oxygen uptake $\left(\mathrm{VO}_{2}\right)$ and carbon dioxide production $\left(\mathrm{VCO}_{2}\right)$ were determined. A 12-lead ECG was continuously monitored, whereas blood pressure was automatically measured every $2 \mathrm{~min}$. The gas analyzers were calibrated for both accuracy and linearity prior to each test. Exercise tests were repeated at 3 and 12 months.

\section{Intervention}

\section{Diet}

All intervention groups received the same diet program. An individual hypocaloric diet was prescribed, based on measured resting metabolic rate (RMR) using a ventilated hood system (Oxycon Beta; Erich Jaeger $)$. Caloric intake was $(\mathrm{RMR} \times 1.3)-600 \mathrm{kcal} /$ day. During the first 3 months participants had a dietary counseling every fortnight. During the next 3 months there was a dietary counseling once a month. During the last 6 months (follow-up) there were 3 more visits to the dietician (bi-monthly).

\section{Fitness Training}

The fitness training program consisted of aerobic interval training and consistent aerobic exercise $(70-80 \%$ of maximal measured heart rate (HRmax)) combined with general muscle strengthening exercises for the large muscle groups of the body. During the first 3 months there were two 1-hour group training sessions in the hospital every week. All training sessions were lead by the same physiotherapist. Walking, running, cycling and stepping were the exercises mostly used. Heart rate monitors (Polar, Oulu, Finland) with individual heart rate target zones were worn during training sessions in the hospital. Participants were instructed to exercise a third time at home or in a fitness or sports club. During the next 3 months there was only 1 weekly training session of $1 \mathrm{~h}$ in the hospital. Participants were encouraged to exercise a second and third time at home or in a fitness or sports club and to increase their daily physical activity. In the follow-up period (6-12 months) participants were advised to maintain an active lifestyle and to meet bi-monthly with the study dietician.

\section{$W B V$}

A group training was performed on a WBV platform (Power Plate, Badhoevendorp, the Netherlands). A training protocol was designed with a gradual increase in frequency $(30-35-40 \mathrm{~Hz})$, amplitude (low-high), time/exercise ( $30-45-60 \mathrm{~s})$ and number of exercises (10-22 exercises). Resting time between exercises always equaled exercise time. During the first 3 months the mean total exercise time per session was $11.9 \mathrm{~min}$. In the next 3 months the mean total exercise time per session increased to $14.2 \mathrm{~min}$. In the first 3 months the program consisted of static exercises (exercises in which the joint angle and muscle length do not change during contraction), while in the next 3 months the exercises were executed dynamically. Exercises were chosen to train all major muscle groups. All training sessions were lead by a physiotherapist to ensure correct performance of the exercises. A training session typically included: squatting, deep squatting, calf raises, lunges, curl-ups, push-ups etc. In the follow-up period (6-12 months) participants were advised to maintain an active lifestyle and to meet bi-monthly with the study dietician.

Statistical Analyses

Statistical calculations were performed using the statistical package SPSS version 15.0 for Windows (SPSS, Chicago, IL, USA). Normality of distri- bution was verified with a Kolmogorov-Smirnov test. Changes within groups were analyzed using a paired-samples T test or a Wilcoxon test for non-parametric data. A one-way ANOVA with a post-hoc Bonferroni adjustment was used to evaluate differences in changes between groups. A two-way repeated measures ANOVA with time intervention interaction was used to analyze differences in evolution of weight, BMI, body composition and metabolic parameters between groups. Results were considered significant if $\mathrm{P}<0.05$. Values are expressed as mean $\pm \mathrm{SD}$.

\section{Results}

In the total sample of 79 subjects, 20 were men (25.3\%). Anthropometric characteristics of the 4 study groups at baseline are shown in table 1. Baseline characteristics were not significantly different between groups, except for maximal aerobic capacity where a post-hoc Bonferroni test revealed a significant difference between the VIBRATION group and the DIET group $(\mathrm{P}=0.006)$.

61 subjects completed the study, 18 subjects dropped out of the study $(22.8 \%)$. Drop-out rate was highest in the DIET group ( 8 subjects), followed by the VIBRATION group (5), the CONTROL group (4) and finally the FITNESS group (1). In the DIET group, 4 persons did not adhere to the study protocol and started their own exercise program, 3 persons stopped visiting the study dietician due to a lack of time or financial reasons, and 1 person had to stop because of breast cancer. In the VIBRATION group 1 person dropped out because of financial reasons, 2 persons because of social reasons, 1 person because of phlebitis of the lower leg and 1 person due to a lack in motivation. In the CONTROL group 2 people stopped for unknown and 1 person due to financial reasons; 1 person developed diabetes. In the FITNESS group 1 person dropped due to low back pain.

Anthropometric, metabolic and hemodynamic characteristics of the 4 study groups during the study and follow-up are shown in tables 2 and 3 .

\section{Body Weight and Body Composition}

Body weight decreased significantly after 3,6 or 12 months in the DIET group $(\mathrm{P}=0.003, \mathrm{P}=0.003$ or $\mathrm{P}=0.009)$, the FITNESS group $(\mathrm{P}<0.001, \mathrm{P}<0.001$ or $\mathrm{P}=0.004)$ and the VIBRATION group $(\mathrm{P}<0.001$ in all three cases) compared to body weight at baseline (table 2). There was a significant decrease in body weight from 3 to 6 months in the FITNESS $(-1.8 \pm 2.4 \mathrm{~kg} ; \mathrm{P}=0.012)$ and VIBRATION group $(-2.7 \pm$ $2.5 \mathrm{~kg}$; $\mathrm{P}=0.006)$. Similar results were found for BMI. The evolution in time of body weight was significantly different $(\mathrm{P}<0.001)$ between groups. Also the changes of weight loss over time, expressed as a percentage of initial weight, were significantly different $(\mathrm{P}<0.001)$ between groups. (fig. 1)

There was a significant decrease in \%body fat after 3 months in the FITNESS group $(\mathrm{P}<0.001)$ and the VIBRATION group $(\mathrm{P}=0.012)$ compared to \%body fat at baseline. There was a significant decrease in \%body fat after 6 or 12 
Table 2. Anthropometric characteristics at baseline and after intervention and follow-up (compared to baseline).

\begin{tabular}{|c|c|c|c|c|c|c|c|}
\hline Variables & 0 months & $\Delta 3$ months & $\mathrm{P}$ & $\Delta 6$ months & $\mathrm{P}$ & $\Delta 12$ months & $\mathrm{P}$ \\
\hline \multicolumn{8}{|l|}{ Weight, $k g$} \\
\hline Control & $84.5 \pm 13.2$ & $+0.6 \pm 2.7$ & $<0.001^{\mathrm{a}}$ & $+0.9 \pm 3.4$ & $<0.001^{\mathrm{a}}$ & $+1.3 \pm 3.7$ & $<0.001^{\mathrm{a}}$ \\
\hline Diet & $93.0 \pm 12.3$ & $-5.7 \pm 4.7$ & $0.245^{\mathrm{b}}$ & $-6.1 \pm 4.6$ & $0.097^{\mathrm{b}}$ & $-4.3 \pm 4.8$ & $0.080^{\mathrm{b}}$ \\
\hline Fitness & $94.5 \pm 11.7$ & $-5.3 \pm 3.6$ & & $-7.0 \pm 5.6$ & & $-6.6 \pm 6.4$ & \\
\hline Vibration & $94.3 \pm 18.6$ & $-7.6 \pm 2.9$ & & $-10.3 \pm 4.6$ & & $-9.9 \pm 6.2$ & \\
\hline \multicolumn{8}{|c|}{$B M I, \mathrm{~kg} / \mathrm{m}^{2}$} \\
\hline Control & $29.8 \pm 2.6$ & $+0.3 \pm 0.9$ & $<0.001^{\mathrm{a}}$ & $+0.4 \pm 1.2$ & $<0.001^{\mathrm{a}}$ & $+0.4 \pm 1.4$ & $<0.001^{\mathrm{a}}$ \\
\hline Diet & $33.6 \pm 3.3$ & $-2.0 \pm 1.7$ & $0.365^{\mathrm{b}}$ & $-1.6 \pm 2.3$ & $0.064^{\mathrm{b}}$ & $-1.5 \pm 1.7$ & $0.085^{\mathrm{b}}$ \\
\hline Fitness & $33.1 \pm 3.4$ & $-1.9 \pm 1.2$ & & $-2.5 \pm 1.9$ & & $-2.3 \pm 2.1$ & \\
\hline Vibration & $31.2 \pm 4.5$ & $-2.5 \pm 1.0$ & & $-3.4 \pm 1.6$ & & $-3.4 \pm 2.0$ & \\
\hline \multicolumn{8}{|l|}{$V A T, \mathrm{~cm}^{2}$} \\
\hline Control & $111.5 \pm 47.6$ & $+2.4 \pm 20.0$ & $0.005^{\mathrm{a}}$ & $-3.6 \pm 20.5$ & $0.005^{\mathrm{a}}$ & $+26.3 \pm 30.6$ & $<0.001^{\mathrm{a}}$ \\
\hline Diet & $134.8 \pm 57.3$ & $-31.4 \pm 31.9$ & $0.630^{\mathrm{b}}$ & $-26.3 \pm 29.2$ & $0.076^{\mathrm{b}}$ & $-4.9 \pm 27.0$ & $0.003^{\mathrm{b}}$ \\
\hline Fitness & $116.0 \pm 44.8$ & $-23.0 \pm 28.4$ & & $-17.5 \pm 36.5$ & & $-1.5 \pm 33.3$ & \\
\hline Vibration & $159.9 \pm 89.8$ & $-21.3 \pm 24.1$ & & $-47.8 \pm 41.2$ & & $-47.8 \pm 45.7$ & \\
\hline \multicolumn{8}{|l|}{$T A T, \mathrm{~cm}^{2}$} \\
\hline Control & $459.5 \pm 113.8$ & $+9.2 \pm 41.6$ & $<0.001^{\mathrm{a}}$ & $+12.8 \pm 55.9$ & $<0.001^{\mathrm{a}}$ & $+44.6 \pm 64.2$ & $<0.001^{\mathrm{a}}$ \\
\hline Diet & $666.1 \pm 108.7$ & $-94.8 \pm 59.2$ & $0.686^{\mathrm{b}}$ & $-87.8 \pm 49.3$ & $0.018^{\mathrm{b}}$ & $-51.5 \pm 47.8$ & $0.044^{\mathrm{b}}$ \\
\hline Fitness & $614.5 \pm 97.1$ & $-86.0 \pm 52.6$ & & $-87.3 \pm 84.4$ & & $-70.4 \pm 88.4$ & \\
\hline Vibration & $599.3 \pm 136.6$ & $-104.5 \pm 67.2$ & & $-154.4 \pm 53.5$ & & $-133.2 \pm 96.3$ & \\
\hline \multicolumn{8}{|l|}{ BIA Fat $\%$} \\
\hline Control & $40.3 \pm 7.6$ & $+0.4 \pm 2.5$ & $0.003^{\mathrm{a}}$ & $0.6 \pm 2.9$ & $<0.001^{\mathrm{a}}$ & $-0.9 \pm 2.7$ & $<0.001^{\mathrm{a}}$ \\
\hline Diet & $49.2 \pm 7.1$ & $-1.2 \pm 6.3$ & $0.150^{\mathrm{b}}$ & $-3.8 \pm 2.7$ & $0.069^{\mathrm{b}}$ & $-2.7 \pm 1.9$ & $0.244^{\mathrm{b}}$ \\
\hline Fitness & $47.0 \pm 5.6$ & $-3.8 \pm 2.7$ & & $-4.4 \pm 3.4$ & & $-4.0 \pm 4.1$ & \\
\hline Vibration & $42.8 \pm 7.2$ & $-4.8 \pm 4.9$ & & $-7.0 \pm 4.3$ & & $-5.5 \pm 5.1$ & \\
\hline \multicolumn{8}{|l|}{$W H R$} \\
\hline Control & $0.90 \pm 0.11$ & $0.00 \pm 0.02$ & $0.004^{\mathrm{a}}$ & $0.00 \pm 0.04$ & $0.021^{\mathrm{a}}$ & $+0.01 \pm 0.03$ & $0.002^{\mathrm{a}}$ \\
\hline Diet & $0.90 \pm 0.11$ & $-0.01 \pm 0.01$ & $0.048^{\mathrm{b}}$ & $-0.01 \pm 0.03$ & $0.023^{b}$ & $0.00 \pm 0.03$ & $0.013^{\mathrm{b}}$ \\
\hline Fitness & $0.89 \pm 0.10$ & $-0.01 \pm 0.04$ & & $-0.01 \pm 0.04$ & & $-0.02 \pm 0.04$ & \\
\hline Vibration & $0.90 \pm 0.11$ & $-0.04 \pm 0.04$ & & $-0.05 \pm 0.05$ & & $-0.05 \pm 0.05$ & \\
\hline
\end{tabular}

months in the DIET group $(\mathrm{P}=0.003$ after both time periods), the FITNESS group $(\mathrm{P}<0.001$ or $\mathrm{P}=0.003)$ and the VIBRATION group $(\mathrm{P}<0.001$ or $\mathrm{P}=0.009)$ compared to $\%$ body fat at baseline (table 2 ). Changes in \% body fat over time were significantly different $(\mathrm{P}<0.001)$ between the study groups.

VAT did not change significantly during the first 6 months in the CONTROL group but increased significantly after 12 months compared to baseline $\left(137.8 \pm 55.8 \mathrm{~cm}^{2}\right.$ compared to $\left.111.5 \pm 47.6 \mathrm{~cm}^{2} ; \mathrm{P}=0.003\right)$. VAT significantly decreased after 3 months in all three intervention groups compared to baseline: in the DIET group $\left(109.0 \pm 37.6 \mathrm{~cm}^{2}\right.$ compared to $\left.140.4 \pm 58.0 \mathrm{~cm}^{2} ; \mathrm{P}=0.006\right)$, in the FITNESS group $(93.0 \pm$ $32.1 \mathrm{~cm}^{2}$ compared to $\left.116.0 \pm 44.8 \mathrm{~cm}^{2} ; \mathrm{P}=0.002\right)$ and in the VIBRATION group $\left(130.9 \pm 83.3 \mathrm{~cm}^{2}\right.$ compared to $169.9 \pm$ $\left.90 \mathrm{~cm}^{2} ; \mathrm{P}<0.001\right)$. After 6 months VAT was still significantly decreased compared to baseline in the DIET group (114.2 \pm $\left.44.7 \mathrm{~cm}^{2} ; \mathrm{P}=0.010\right)$ and in the VIBRATION group (112 \pm $\left.57.8 \mathrm{~cm}^{2} ; \mathrm{P}=0.001\right)$; the decrease in the FITNESS group was borderline significant $\left(98.4 \pm 33.6 \mathrm{~cm}^{2} ; \mathrm{P}=0.051\right)$. After 12 months VAT was significantly increased compared to 6 months in the DIET $\left(135.5 \pm 46.2 \mathrm{~cm}^{2} ; \mathrm{P}=0.001\right)$ and the FITNESS $\left(115.7 \pm 44.0 \mathrm{~cm}^{2} ; \mathrm{P}=0.014\right)$ groups. Only the VIBRATION group showed a significant decrease in VAT after 12 months compared to baseline $\left(113.4 \pm 62.9 \mathrm{~cm}^{2}\right.$; $\mathrm{P}=0.004)$. Changes in VAT over time were significantly different ( $\mathrm{P}<0.001)$ between groups (fig. 2).

VIBRATION was the only group in which WHR significantly decreased after 3 months $(0.86 \pm 0.10 ; \mathrm{P}=0.006)$, 6 months $(0.85 \pm 0.10 ; \mathrm{P}=0.007)$ and 12 months $(0.86 \pm 0.11$; $\mathrm{P}=0.003)$ compared to baseline $(0.90 \pm 0.11)$. 
Table 3. Metabolic syndrome characteristics at baseline and after intervention and follow-up (compared to baseline)

\begin{tabular}{|c|c|c|c|c|c|c|c|}
\hline Variables & 0 months & $\Delta 3$ months & $\mathrm{P}$ & $\Delta 6$ months & $\mathrm{P}$ & $\Delta 12$ months & $\mathrm{P}$ \\
\hline \multicolumn{8}{|l|}{ Waist, $\mathrm{cm}$} \\
\hline Control & $97.1 \pm 9.3$ & $+0.5 \pm 2.3$ & $<0.001^{\mathrm{a}}$ & $+0.3 \pm 3.1$ & $<0.001^{\mathrm{a}}$ & $+0.5 \pm 4.0$ & $<0.001^{\mathrm{a}}$ \\
\hline Diet & $102.2 \pm 8.9$ & $-4.1 \pm 2.6$ & $0.220^{\mathrm{b}}$ & $-4.1 \pm 4.0$ & $0.046^{\mathrm{b}}$ & $-3.5 \pm 3.8$ & $0.086^{\mathrm{b}}$ \\
\hline Fitness & $103.5 \pm 9.5 \pm$ & $-5.6 \pm 4.9$ & & $-6.7 \pm 6.1$ & & $-6.9 \pm 7.4$ & \\
\hline Vibration & $100.5 \pm 15.3$ & $-7.1 \pm 3.9$ & & $-9.6 \pm 4.7$ & & $-9.5 \pm 6.3$ & \\
\hline \multicolumn{8}{|c|}{$\mathrm{SBP}, \mathrm{mm} \mathrm{Hg}$} \\
\hline Control & $119 \pm 17$ & $-1 \pm 15$ & $0.774^{\mathrm{a}}$ & $-2 \pm 19$ & $0.365^{\mathrm{a}}$ & $+4 \pm 16$ & $0.213^{\mathrm{a}}$ \\
\hline Diet & $127 \pm 17$ & $-2 \pm 15$ & $0.783^{\mathrm{b}}$ & $+3 \pm 20$ & $0.245^{\mathrm{b}}$ & $-1 \pm 19$ & $0.596^{\mathrm{b}}$ \\
\hline Fitness & $121 \pm 18$ & $-5 \pm 21$ & & $-8 \pm 14$ & & $-5 \pm 20$ & \\
\hline Vibration & $134 \pm 21$ & $-8 \pm 17$ & & $-8 \pm 18$ & & $-10 \pm 15$ & \\
\hline \multicolumn{8}{|c|}{$\mathrm{DBP}, \mathrm{mm} \mathrm{Hg}$} \\
\hline Control & $68 \pm 11$ & $-1 \pm 9$ & $0.322^{\mathrm{a}}$ & $-1 \pm 10$ & $0.192^{\mathrm{a}}$ & $+2 \pm 9$ & $0.438^{\mathrm{a}}$ \\
\hline Diet & $80 \pm 29$ & $-10 \pm 27$ & $0.770^{\mathrm{b}}$ & $-6 \pm 25$ & $0.326^{\mathrm{b}}$ & $-7 \pm 29$ & $0.930^{\mathrm{b}}$ \\
\hline Fitness & $78 \pm 19$ & $-11 \pm 18$ & & $-13 \pm 20$ & & $-7 \pm 19$ & \\
\hline Vibration & $78 \pm 12$ & $-6 \pm 11$ & & $-3 \pm 10$ & & $-5 \pm 11$ & \\
\hline \multicolumn{8}{|l|}{$F G, m g / d l$} \\
\hline Control & $83.6 \pm 8.7$ & $+2.8 \pm 6.7$ & $0.585^{\mathrm{a}}$ & $+2.7 \pm 7.8$ & $0.829^{\mathrm{a}}$ & $+3.6 \pm 7.7$ & $0.291^{\mathrm{a}}$ \\
\hline Diet & $87.8 \pm 7.0$ & $-0.3 \pm 9.4$ & $0.221^{\mathrm{b}}$ & $+0.3 \pm 8.7$ & $0.830^{\mathrm{b}}$ & $+4.2 \pm 8.0$ & $0.808^{b}$ \\
\hline Fitness & $82.4 \pm 8.7$ & $+2.0 \pm 5.0$ & & $+1.9 \pm 6.1$ & & $+2.9 \pm 12.5$ & \\
\hline Vibration & $83.3 \pm 7.9$ & $+0.7 \pm 4.8$ & & $+1.7 \pm 6.3$ & & $+2.5 \pm 6.3$ & \\
\hline \multicolumn{8}{|l|}{$T G, m g / d l$} \\
\hline Control & $138.5 \pm 66.3$ & $-8.0 \pm 40.3$ & $0.559^{\mathrm{a}}$ & $+9.6 \pm 54.7$ & $0.062^{\mathrm{a}}$ & $+9.0 \pm 65.5$ & $0.089^{\mathrm{a}}$ \\
\hline Diet & $164.4 \pm 50.0$ & $-26.1 \pm 61.4$ & $0.979^{\mathrm{b}}$ & $-30.2 \pm 42.3$ & $0.870^{\mathrm{b}}$ & $-21.7 \pm 50.7$ & $0.726^{\mathrm{b}}$ \\
\hline Fitness & $139.4 \pm 57.5$ & $-26.6 \pm 46.6$ & & $-33.2 \pm 55.2$ & & $-36.4 \pm 46.8$ & \\
\hline Vibration & $126.4 \pm 48.7$ & $-29.8 \pm 33.6$ & & $-23.8 \pm 40.7$ & & $-32.3 \pm 51.0$ & \\
\hline \multicolumn{8}{|c|}{$H D L-C, m g / d l$} \\
\hline Control & $56.9 \pm 13.6$ & $-3.0 \pm 8.4$ & $0.102^{\mathrm{a}}$ & $-2.3 \pm 5.5$ & $0.001^{\mathrm{a}}$ & $+0.8 \pm 10.1$ & $0.188^{\mathrm{a}}$ \\
\hline Diet & $58.4 \pm 13.9$ & $+0.6 \pm 7.0$ & $0.103^{\mathrm{b}}$ & $+4.8 \pm 7.0$ & $0.065^{\mathrm{b}}$ & $+5.3 \pm 9.4$ & $0.561^{\mathrm{b}}$ \\
\hline Fitness & $57.1 \pm 15.2$ & $+2.7 \pm 8.6$ & & $+7.6 \pm 8.0$ & & $+8.8 \pm 7.6$ & \\
\hline Vibration & $61.1 \pm 14.4$ & $-3.8 \pm 7.6$ & & $+1.0 \pm 6.6$ & & $+5.0 \pm 14.0$ & \\
\hline
\end{tabular}

\section{Components of the Metabolic Syndrome}

Waist circumference significantly decreased in all 3 intervention groups after 3, 6 and 12 months compared to baseline. Waist circumference decreased most in the VIBRATION group (table 2). In this group the waist circumference also decreased from 3 to 6 months $(P=0.018)$. Changes in waist circumference over time were significantly different $(\mathrm{P}=0.001)$ between groups.

There were no significant changes in systolic blood pressure (SBP) in the CONTROL and DIET groups. SBP decreased significantly in the FITNESS group after 3 months compared to baseline $(116 \pm 9 \mathrm{~mm} \mathrm{Hg}$ compared to $121 \pm$ $19 \mathrm{~mm} \mathrm{Hg} ; \mathrm{P}=0.032$ ) and in the VIBRATION group after 12 months compared to baseline $(123 \pm 15 \mathrm{~mm} \mathrm{Hg}$ vs. $133 \pm$ $21 \mathrm{~mm} \mathrm{Hg}$; $\mathrm{P}=0.037)$. There were no significant changes in diastolic blood pressure (DBP) in the CONTROL and DIET groups. DBP changed significantly in the FITNESS group after 3 months $(67 \pm 9 \mathrm{~mm} \mathrm{Hg} ; \mathrm{P}=0.024)$ and 6 months $(66 \pm$ $8 \mathrm{~mm} \mathrm{Hg} ; \mathrm{P}=0.014)$ compared to baseline (78 $\pm 19 \mathrm{~mm} \mathrm{Hg})$.

There were no significant changes in fasting glucose in the 4 study groups, except for a significant increase in the DIET group after 12 months compared to that after 6 months (91.8 $\pm 8.8 \mathrm{mg} / \mathrm{dl}$ vs. $87.8 \pm 8.4 \mathrm{mg} / \mathrm{dl} ; \mathrm{P}=0.033)$.

HDL-C did not change significantly in the CONTROL group during the study period and follow-up. In the DIET group there was a significant increase after 6 months compared to that after 3 months $(63.2 \pm 14.6 \mathrm{mg} / \mathrm{dl}$ vs. $59.0 \pm$ $15.1 \mathrm{mg} / \mathrm{dl} ; \mathrm{P}=0.027)$ and compared to baseline $(58.4 \pm$ $13.9 \mathrm{mg} / \mathrm{dl} ; \mathrm{P}=0.039$ ). The largest changes in HDL-C occurred in the FITNESS group: HDL-C increased highly significantly after 6 months $(64.7 \pm 14.8 \mathrm{mg} / \mathrm{dl} ; \mathrm{P}=0.001)$ and 12 months $(63.2 \pm 11.7 \mathrm{mg} / \mathrm{dl} ; \mathrm{P}<0.001)$ compared to baseline 


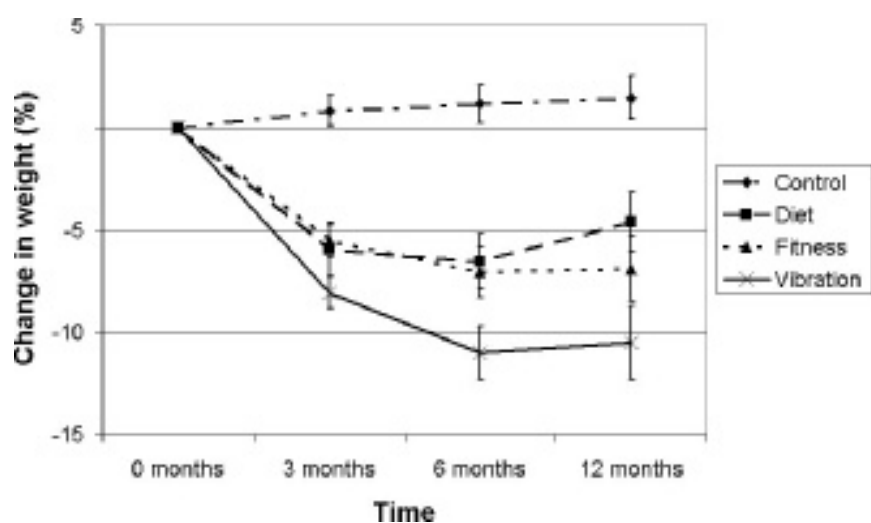

Fig. 1. Weight loss, expressed as a percentage of initial weight, changed significantly different between the 4 study groups $(\mathrm{P}<0.001)$. Error bars represent standard error of means.

$(57.1 \pm 15.3 \mathrm{mg} / \mathrm{dl})$, and also showed a significant increase after 6 months compared to that after 3 months $(59.7 \pm$ $15.7 \mathrm{mg} / \mathrm{dl} ; \mathrm{P}=0.004)$. In the VIBRATION group there was a significant increase of HDL-C after 6 months compared to that after 3 months $(63.5 \pm 16.8 \mathrm{mg} / \mathrm{dl}$ compared to $58.4 \pm$ $13.3 \mathrm{mg} / \mathrm{dl} ; \mathrm{P}=0.015)$.

Triglycerides did not change significantly in the CONTROL group during the study period and follow-up. In the DIET group triglycerides decreased significantly after 6 months compared to baseline $(134.3 \pm 37.1 \mathrm{mg} / \mathrm{dl}$ compared to $164.4 \pm 50.0 \mathrm{mg} / \mathrm{dl} ; \mathrm{P}=0.031)$. In the FITNESS group the largest changes in triglycerides occurred: there was a significant decrease in triglycerides after 3 months $(112.8 \pm 45.2 \mathrm{mg} / \mathrm{dl}$ $\mathrm{P}=0.023)$, after 6 months $(106.2 \pm 37.3 \mathrm{mg} / \mathrm{dl} ; \mathrm{P}=0.017)$ and after 12 months $(104.9 \pm 47.5 \mathrm{mg} / \mathrm{dl} ; \mathrm{P}=0.006)$ compared to baseline $(139.4 \pm 57.5 \mathrm{mg} / \mathrm{dl})$. In the VIBRATION group there was a significant decrease of TG after 3 months compared to baseline $(96.7 \pm 42.2 \mathrm{mg} / \mathrm{dl}$ compared to $126.4 \pm$ $48.7 \mathrm{mg} / \mathrm{dl}$; $\mathrm{P}=0.011$ ). The evolution in time of triglycerides was not significantly different between groups.

\section{Aerobic Capacity}

In the FITNESS group maximal $\mathrm{VO}_{2}\left(\mathrm{VO}_{2} \mathrm{max}\right)$ increased after 3 months $(27.0 \pm 6.4 \mathrm{ml} / \mathrm{kg} / \mathrm{min} ; \mathrm{P}=0.021)$ and after 12 months $(28.8 \pm 4.7 \mathrm{ml} / \mathrm{kg} / \mathrm{min} ; \mathrm{P}<0.001)$ compared to baseline $(24.2 \pm 2.5 \mathrm{ml} / \mathrm{kg} / \mathrm{min})$. In the other two intervention groups there were no significant changes in $\mathrm{VO}_{2}$ max. The evolution over time of $\mathrm{VO}_{2}$ max was not significantly different between the 3 intervention groups.

\section{Discussion}

In this study we demonstrated that adding aerobic exercise or WBV to a hypocaloric diet can help to maintain weight loss. Moreover, the addition of WBV seems to initiate an even

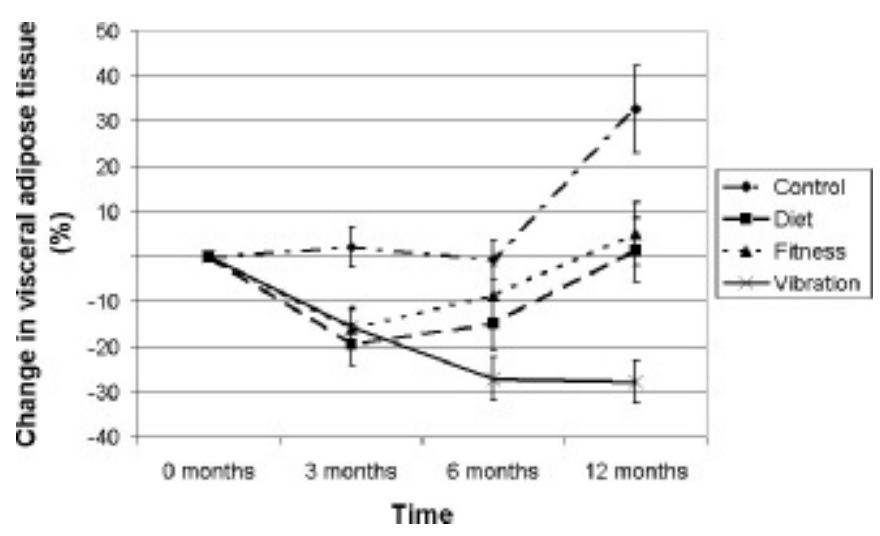

Fig. 2. Visceral adipose tissue changed significantly different between the 4 study groups $(\mathrm{P}<0.001)$. Error bars represent standard error of means.

larger loss of VAT. To the best of our knowledge this is the first time that such findings are reported in a clinical trial. This may be of clinical importance since VAT plays a central role in metabolic syndrome. In their review, Avenell et al. [24] reported that diet and exercise were associated with a weight change at 12 months of between $-1.95 \mathrm{~kg}$ and $-5.32 \mathrm{~kg}$, compared with $-4.82 \mathrm{~kg}$ in the diet only group. In our study weight loss at 12 months was markedly higher in the FITNESS group $(-6.62 \mathrm{~kg})$ and in the VIBRATION group $(-10.18 \mathrm{~kg})$. In the DIET group weight loss was $-4.07 \mathrm{~kg}$. Since Douketis et al. [25] stated in their review that almost no dietary/lifestyle therapy study reported on $\geq 5 \%$ weight loss, we found it clinically relevant to report weight loss efficacy this way. The diet only group was unable to maintain a weight loss of $\geq 5 \%$ at 12 months, where the FITNESS group succeeded in doing so. The VIBRATION group was the only group to succeed a weight loss of $\geq 10 \%$ at 6 months and maintain at 12 months. According to the guidelines of the European Association for the Study of Obesity (EASO), a modest weight loss (i.e. $5-10 \%$ of initial body weight), improved nutritional content of the diet and modest increases in physical activity and fitness are important in achieving risk reduction and health improvement [7].

Although there are studies that report no alleviation of the metabolic syndrome by adding exercise (walking or resistance training) to diet counseling [26], other studies showed that adding aerobic exercise training to a dietary weight reduction program further improves metabolic syndrome components compared with diet alone [27]. Some researchers state that exercise intensity is an important factor for reversing the risk factors of metabolic syndrome [28]. Resistance training can improve metabolic risk factors. Jurca et al. [17] described resistance exercise as a potential means for preventing metabolic syndrome, based on the inverse association of muscle strength and metabolic syndrome. Few studies looked at the effect of resistance training on metabolic syndrome as a pri- 
mary goal but Levinger et al. [29] concluded that resistance training should be added to other nonpharmacological interventions for metabolic risk factors such as aerobic training and/or diet [29]. Moreover, resistance training seems to have a potentially positive effect on visceral fat $[30,31]$. WBV training is a viable alternative for resistance training. Roelants et al. [32] reported the gain in strength following WBV training to be comparable to the strength increase following a standard fitness training program consisting of cardiovascular and resistance training. There is strong to moderate evidence that long-term WBV exercise has positive effects on the leg muscular performance among untrained people and elderly women [18]. Recent findings show that WBV reduced body fat accumulation and serum leptin without affecting muscle function or food consumption in Fischer rats [33]. Interestingly, Rubin et al. [20] recently reported that adipogenesis is inhibited in mice by brief, daily exposure to low-magnitude mechanical signals, delivered via WBV. Although there were no significant differences in VAT and waist circumference at baseline between the study groups, the authors acknowledge the fact that abdominal fat reduction can be modified by obesity phenotype in response to weight loss, as reported by Okura et al. [34]. Therefore, the higher amount of VAT at baseline in the vibration group, although not significantly higher compared to the other groups, could possibly have had an effect on the reduction in VAT throughout the intervention period. Although Roelants et al. [32] found that WBV training induces a small increase in fat free mass, they found that it did not reduce weight, total body fat or subcutaneous fat in previously untrained females. In contrast, we found that adding WBV to diet can help to reduce weight, fat percentage and VAT in particular. The underlying mechanism by which WBV can have an effect on visceral fat remains unclear. However, there are some possible contributing factors: 10 sets of $60 \mathrm{~s}$ WBV stimuli increase serum free fatty acid concentration during the recovery period [35]. Furthermore, acute exposure to WBV activates the central sympathetic nervous system (SNS) [36]. One key role of the SNS innervation of white adipose tissue is to trigger lipolysis. There is an association be- tween a low SNS activity and a low lipid oxidation, and a low SNS activity is a risk factor for weight gain in humans [37]. When trying to explain the effects of WBV, it should be noted that WBV may elicit secondary responses through interaction among different systems: the skeletal, muscular, endocrine, nervous and vascular systems [38].

There are some limitations of the present study that need to be acknowledged. The initial group sizes were small for a long-term study. We were unable to include exercise tests for the CONTROL group. Although total exercise time was comparable in the FITNESS and VIBRATION groups, there was an unequal amount of intervention sessions between these groups. Despite its limitations this study is the first to look at the mid- and long-term effects of WBV training on weight, body composition and metabolic risk factors in overweight and obese adults.

Based upon our findings we conclude that both aerobic exercise and WBV training, in addition to a hypocaloric diet, can help to achieve a sustained mid-term (6 months) and longterm (12 months) weight loss of $5-10 \%$. When combined with a hypocaloric diet, WBV training seems to have the potential to reduce waist circumference, WHR and VAT to a greater extent than aerobic exercise. However, aerobic exercise seems to have a stronger effect on HDL-C, triglycerides and aerobic capacity. Therefore, these preliminary data suggest that a combined approach of both aerobic exercise and WBV can potentially be included in future weight loss programs. However, more controlled trials will have to be performed in order to confirm these data.

\section{Acknowledgement}

This study was funded by a doctoral grant sponsored by the Artesis University College of Antwerp, Belgium.

\section{Disclosure}

The authors declared no financial interest.

\section{References}

1 Branca F, Nikogosian H, Lobstein T (eds): The Challenge of Obesity in the WHO European Region and the Strategies for Response: Summary. Copenhagen, WHO Regional Office for Europe, 2007.

$\checkmark 2$ Flegal KM, Carroll MD, Kuczmarski RJ, Johnson CL: Overweight and obesity in the United States: prevalence and trends, 1960-1994. Int J Obes Relat Metab Disord 1998;22:39-47.

3 Bosello O, Zamboni M: Visceral obesity and metabolic syndrome. Obes Rev 2000;1:47-56.

4 Eckel RH, Grundy SM, Zimmet PZ: The metabolic syndrome. Lancet 2005;365:1415-1428.

$\checkmark 5$ Van Gaal LF, Mertens IL, De Block CE: Mechanisms linking obesity with cardiovascular disease. Nature 2006;444:875-880.
6 Grundy SM, Cleeman JI, Daniels SR, Donato KA, Eckel RH, Franklin BA, Gordon DJ, Krauss RM, Savage PJ, Smith SC Jr, Spertus JA, Costa F: Diagnosis and management of the metabolic syndrome: an American Heart Association/National Heart, Lung, and Blood Institute scientific statement: executive summary. Circulation 2005;112:e285-290.

7 Tsigos C, Hainer V, Basdevant A, Finer N, Friede M, Mathus-Vliegen E, Micic D, Maislos M, Roman G, Schutz Y, Toplak H, Zahorska-Markiewicz B, for the Obesity Management Task Force of the European Association for the Study of Obesity: Management of obesity in adults: European clinical practice guidelines Obes Facts 2008;1:106-116.
8 Van Gaal LF, Wauters MA, Leeuw De IH: The beneficial effects of modest weight loss on cardiovascular risk factors. Int J Obes Relat Metab Disord. 1997;21(suppl 1):S5-S9.

$\checkmark$ Case CC, Jones PH, Nelson K, O'Brian Smith E, Ballantyne CM: Impact of weight loss on the metabolic syndrome. Diabetes Obes Metable 2002;4: 407-414.

10 Lee S, Kuk JL, Davidson LE, Hudson R, Kilpatrick K, Graham TE, Ross R: Exercise without weight loss is an effective strategy for obesity reduction in obese individuals with and without type 2 diabetes. J Appl Physiol 2005;99:1220-1225. 
11 DiPietro L: Physical activity in the prevention of obesity: current evidence and research issues. Med Sci Sports Exerc 1999;31(11 suppl):S542-546.

12 Wing RR: Physical activity in the treatment of the adulthood overweight and obesity: current evidence and research issues. Med Sci Sports Exerc 1999;31 (11 suppl):S547-552.

13 Haslam DW, James WP: Obesity. Lancet. 2005;366: 1197-1209.

14 Fogelholm M, Kukkonen-Harjula K: Does physical activity prevent weight gain - a systematic review. Obes Rev 2000;1:95-111.

15 Garrow JS, Summerbell CD: Meta-analysis: effect of exercise, with or without dieting, on the body composition of overweight subjects. Eur J Clin Nutr 1995;49:1-10.

16 Lakka TA, Laaksonen DE, Lakka HM, Mannikko N, Niskanen LK, Rauramaa R, Salonen JT: Sedentary lifestyle, poor cardiorespiratory fitness, and the metabolic syndrome. Med Sci Sports Exerc 2003; 35:1279-1286.

-17 Jurca R, Lamonte MJ, Barlow CE, Kampert JB, Church TS, Blair SN: Association of muscular strength with incidence of metabolic syndrome in men. Med Sci Sports Exerc 2005;37:1849-1855.

18 Rehn B, Lidstrom J, Skoglund J, Lindstrom B: Effects on leg muscular performance from wholebody vibration exercise: a systematic review. Scand J Med Sci Sports 2007;17:2-11.

19 Mester J, Kleinoder H, Yue Z: Vibration training: benefits and risks. J Biomech 2005;39:1056-1065.

20 Rubin CT, Capilla E, Luu YK, Busa B, Crawford H, Nolan DJ, Mittal V, Rosen CJ, Pessin JE, Judex $\mathrm{S}$ : Adipogenesis is inhibited by brief, daily exposure to high-frequency, extremely low-magnitude mechanical signals. Proc Natl Acad Sci U S A 2007; 104:17879-17884.

21 Lukaski HC, Johnson PE, Bolonchuk WW, Lykken GI: Assessment of fat-free mass using bioelectrical impedance measurements of the human body. Am J Clin Nutr 1985;41:810-817.
22 Deurenberg P, Weststrate JA, van der Kooy K: Body composition changes assessed by bioelectrical impedance measurements. Am J Clin Nutr 1989; 49:401-403.

23 van der Kooy K, Seidell JC: Techniques for the measurement of visceral fat: a practical guide. Int J Obes Relat Metab Disord 1993;17:187-196.

24 Avenell A, Brown TJ, McGee MA, Campbell MK, Grant AM, Broom J, Jung RT, Smith WCS: What interventions should we add to weight reducing diets in adults with obesity? A systematic review of randomized controlled trials of adding drug therapy, exercise, behaviour therapy or combinations of these interventions. J Hum Nutr Dietet 2004; 17:293-316.

25 Douketis JD, Macie C, Thabane L, Williamson DF: Systematic review of long-term weight loss studies in obese adults: clinical significance and applicability to clinical practice. Int J Obes (Lond) 2005; 29:1153-1167.

26 Kukkonen-Harjula KT, Borg PT, Nenonen AM, Fogelholm MG: Effects of a weight maintenance program with or without exercise on the metabolic syndrome: a randomized trial in obese men. Prev Med 2005;41:784-790

27 Okura T, Nakata Y, Ohkawara K, Numao S, Katayama Y, Matsuo T, Tanaka K: Effects of aerobic exercise on metabolic syndrome improvement in response to weight reduction. Obesity (Silver Spring) 2007;15:2478-2484.

28 Tjonna AE, Lee SJ, Rognmo O, Stolen TO, Bye A, Haram PM, Loennechen JP, Al-Share QY, Skogvoll E, Slordahl SA, Kemi OJ, Najjar SM, Wisloff U: Aerobic interval training versus continuous moderate exercise as a treatment for the metabolic syndrome: a pilot study. Circulation 2008;118: 346-354.

29 Levinger I, Goodman C, Matthews V, Hare DL, Jerums G, Garnham A, Selig S: BDNF, metabolic risk factors, and resistance training in middle-aged individuals. Med Sci Sports Exerc 2008;40:535-541.
30 Tsuzuku S, Kajioka T, Endo H, Abbott RD, Curb JD, Yano K: Favorable effects of non-instrumental resistance training on fat distribution and metabolic profiles in healthy elderly people. Eur J Appl Physiol 2007;99:549-555.

31 Schmitz KH, Hannan PJ, Stovitz SD, Bryan CJ, Warren M, Jensen MD: Strength training and adiposity in premenopausal women: strong, healthy, and empowered study. Am J Clin Nutr 2007;86: 566-572.

32 Roelants M, Delecluse C, Goris M, Verschueren S: Effects of 24 weeks of whole body vibration training on body composition and muscle strength in untrained females. Int J Sports Med 2004;25:1-5

33 Maddalozzo GF, Iwaniec UT, Turner RT, Rosen CJ, Widrick JJ: Whole-body vibration slows the acquisition of fat in mature female rats. Int J Obes (Lond) 2008;32:1348-1354.

34 Okura T, Nakata Y, Lee DJ, Ohkawara K, Tanaka $\mathrm{K}$ : Effects of aerobic exercise and obesity phenotype on abdominal fat reduction in response to weight loss. Int J Obes (Lond) 2005;29:1259-1266.

35 Goto K, Takamatsu K: Hormone and lipolytic responses to whole body vibration in young men. Jpn J Physiol 2005;55:279-284.

36 Ando H, Noguchi R: Dependence of palmar sweating response and central nervous system activity on the frequency of whole-body vibration. Scand J Work Environ Health 2003;29:216-219.

37 Snitker S, Macdonald I, Ravussin E, Astrup A: The sympathetic nervous system and obesity: role in aetiology and treatment. Obes Rev 2000;1:5-15.

38 Prisby RD, Lafage-Proust MH, Malaval L, Belli A, Vico L: Effects of whole body vibration on the skeleton and other organ systems in man and animal models: what we know and what we need to know. Ageing Res Rev 2008;7:319-329. 